\title{
The application of membrane technology for reuse of process water and minimisation of waste water in a textile washing range
}

\author{
JPvan't Hul* , I G Rácz and T Reith
}

University of Twente, Dept of Chemical Engineering, Separation Technology Group, PO Box 217, 7500 AE Enschede, The Netherlands

Recycling of process streams and reduction of waste disposal using membrane technology in a continuous textile washing process after dyeing with reactive dyes have been investigated theoretically. A mathematical process model of a conventional open-width washing range has been extended by membrane processes to determine the benefits and limitations of the modified washing processes. The concentrations of hydrolysed reactive dyes, sodium chloride, urea and caustic soda have been calculated with this process model. Reverse osmosis for desalination and decolourising and nanofiltration for decolourising have been implemented as membrane technology. Reusing filtered wash water in a previous wash step results in more water saving than recycling to the same wash step according to the process calculations. The total fresh water demand can be reduced by $70 \%$ and the total waste water volume by $90 \%$ compared with the conventional process. Greater reduction of fresh water use is limited by the osmotic pressure difference between the retentate an permeate streams.

\section{INTRODUCTION}

Several processes are carried out in the textile industry to obtain textile products with the desired properties. Excess chemicals used in these processes to meet the desired product properties need to be washed out. The amount of wash water can be more than $100 \mathrm{l} / \mathrm{kg}$ product, resulting in huge streams of waste. At present, in the Netherlands, these waste streams are treated in municipal treatment plants. In the future this procedure will be confronted with rising costs or even be prohibited. At the same time the availability of fresh process water will decrease and its price will increase. A research project (entitled 'Recycling of process streams in the textile industry' sponsored by Senter, Dutch Ministry of Economic Affairs) has now begun which aims to investigate the application of membrane separation in textile washing processes with the intention to recycle water back into the process. This approach should also result in energy conservation as parts of the washing processes are executed at elevated temperatures.

Waste water containing reactive dyes is considered as a problematic waste of the textile industry as these dyes are removed less efficiently when compared with other dye classes by activated sludge sewage treatment works [5]. Moreover, the fixation of the reactive dyes on textile fabrics is low (70\% on average) compared with other dye classes (over $90 \%$ on average). The continuous washing process following a pad-steam reactive dyeing process has been studied here (Figure 1).

\footnotetext{
* To whom any correspondence should be addressed
}

\section{CONVENTION WASHING PROCESS}

\section{Process description}

The pad-steam reactive dyeing process consists of a dyebath and a steamer. In the dyebath the substrate (woven or knitted fabric) is brought into contact with a dye liquor (Figure 1). The fixation (reaction of the dyes with the fabric) occurs in the steamer. The (dry) fabric stream is $1000 \mathrm{~kg} / \mathrm{h}$. The entrapped liquid stream is $0.6 \mathrm{~kg}$ per kg dry fabric. The components which must be washed out to a large extent are listed in Table 1.

Unfixed hydrolysed reactive dyes and auxiliary chemicals need to be washed out in a washing range (Figure 1) to meet the product specifications. The temperature and liquid throughput of the several wash sections in the washing range can be found in Table 2 .

Furthermore, many auxiliary components are used, such as anionic and nonionic detergents, emulsifiers and pH-buffers. At present it is not feasible to account totally for the presence of these components, since their washingout efficiency in the washing range has not been reported [3]. Their influence in the membrane separation processes will be dealt with in a qualitative way in this study.

The water seal behind the steamer has several functions. It is an effective barrier to oxygen penetration into the steamer. It cools the fabric and it stops the reaction between fabric and dyes. It is also a (small) wash unit. The eight other wash units consist of several compartments each. The fabric is transported through the compartments by guide-rollers. Wash units 1 and 2 must be operated at moderate temperatures $\left(20-30^{\circ} \mathrm{C}\right)$ as higher temperatures, in combination with high $\mathrm{pH}$, may cause already fixed dyes to hydrolyse [4]. In these units the greater part of 


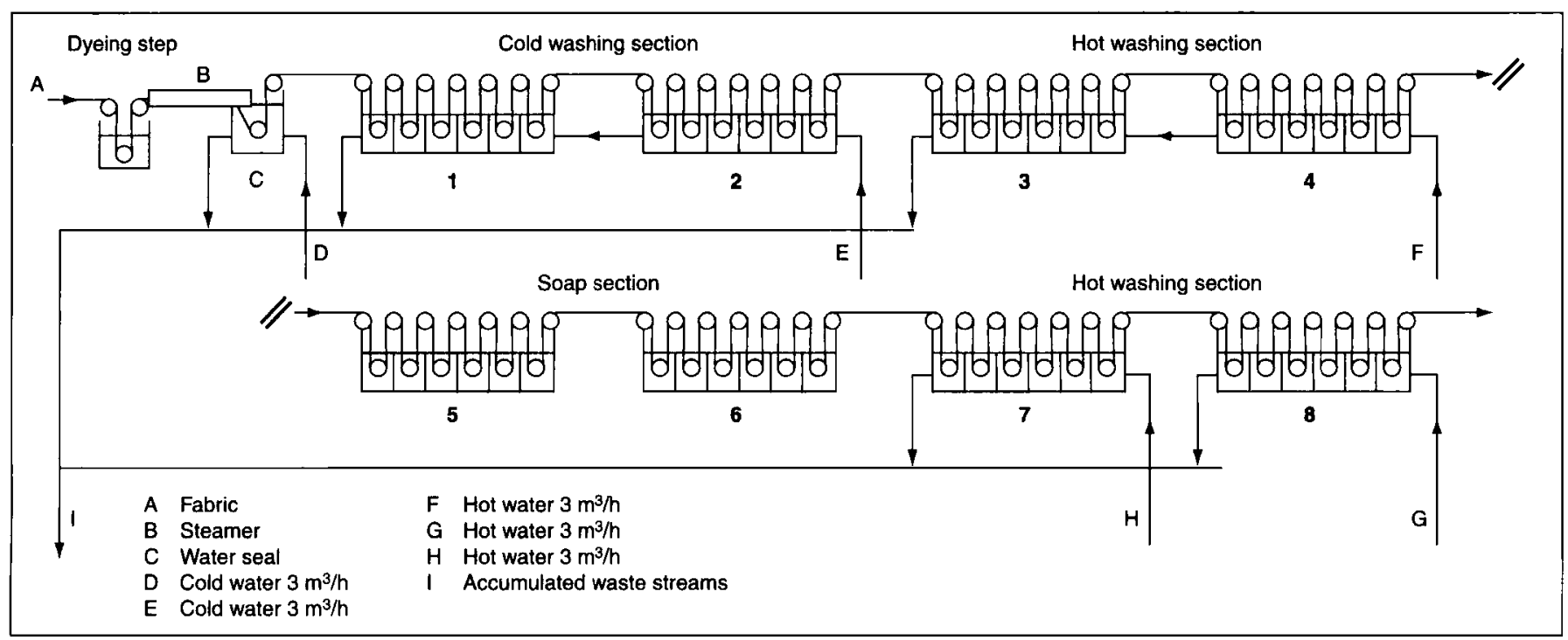

Figure 1 Flow diagram of dyeing step and subsequent open-width washing range of a conventional reactive dyeing process (pad-steam), based on information from Ciba-Geigy [4]

Table 1 Components present in fabric after dyeing

\begin{tabular}{|c|c|c|}
\hline Component & $\begin{array}{l}\text { Concn } \\
\text { (g/kg dry fabric) }\end{array}$ & $\begin{array}{l}\text { Function in } \\
\text { dyeing }\end{array}$ \\
\hline Reactive dyes ${ }^{\mathrm{a}}$ & $3.6^{\mathrm{b}}$ & To dye the fabric \\
\hline Sodium chloride & 150 & To enhance dye uptake \\
\hline Urea & 80 & $\begin{array}{l}\text { To enhance water uptake in } \\
\text { steamer }\end{array}$ \\
\hline Caustic soda & 9.6 & $\begin{array}{l}\text { To enhance reaction between } \\
\text { dye and fabric }\end{array}$ \\
\hline
\end{tabular}

a Unfixed, hydrolysed

b $30 \%$ of total dye uptake in the preceding dyeing step ( $12 \mathrm{~g} / \mathrm{kg}$ per dry fabric )

Table 2 Data on washing process

\begin{tabular}{lll}
\hline $\begin{array}{l}\text { Wash } \\
\text { section }\end{array}$ & $\begin{array}{l}\text { Liquid throughput } \\
\left(\mathrm{m}^{3} / \mathrm{h}\right)\end{array}$ & Temp. $\left({ }^{\circ} \mathrm{C}\right)$ \\
\hline Waterseal (ws) & 3 & 40 \\
Cold (units 1 + 2) & 3 & 20 \\
Hot (units 3 + 4) & 3 & 80 \\
Soap (units 5 +6) & 0 & 80 \\
Hot (unit 7) & 3 & 80 \\
Hot (unit 8) & 3 & 80 \\
\hline
\end{tabular}

sodium chloride, urea and caustic soda are washed out and the $\mathrm{pH}$ drops. The washing out of the unfixed dyes has to be carried out at higher temperatures with soap. Not all the unfixed dyes can be washed out economically and any such dyes remaining can be fixed on the fabric after the washing process by immobilising them with a cationic surfactant.

The final quality of the product is defined by the overall removal of the unfixed dyes. In conventional processes this removal is about $90 \%$. The total quantity of wash water to achieve this removal is $15 \mathrm{l} / \mathrm{kg}$ substrate. It should be mentioned that procedures for textile washing differ from company to company and even from product to product in the same company. This case is taken as a specific example which shows both the benefits and limitations of process water reuse and minimisation of waste water in a textile washing range by processintegrated membrane separation.

\section{Washing efficiency}

A wash unit consists of several compartments (six in this case). A simple model of one compartment is shown in Figure 2. Ideal mixing is assumed in the bulk, the fabric and associated fluid passes through under plug flow conditions.

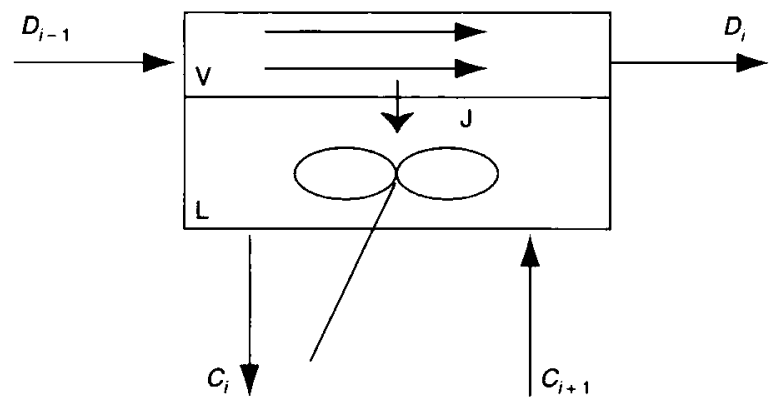

Figure 2 Model of a compartment in a wash unit

A quantitative description of the mass transfer between fabric and liquid is not used in this model as the entrainment of wash water in the fabric is a complicated factor. Therefore, the washing efficiency of each compartment is defined in a similar manner to a Murphree plate efficiency for distillation (Eqn 1) [8]:

$$
M=\frac{D_{i-1}-D_{i}}{D_{i-1}-D_{i}^{*}}
$$


where $D_{i-1}$ and $D_{i}$ are the concentrations of a component, based on dry fabric, in the fabric flow respectively entering and leaving the compartment. $D_{i}^{*}$ is the component concentration in the fabric leaving the compartment which is assumed to be in equilibrium with the wash water. The equilibrium parameter is defined by Eqn 2 :

$$
D_{i}^{*}=m C_{i}
$$

Experimental investigations of a wash compartment have been carried out by Luiken et al. [3]. They calculated efficiencies by assuming $m=1$ (Table 3). The efficiency then becomes Eqn 3:

$$
M=\frac{D_{i-1}-D_{i}}{D_{i-1}-C_{i}}
$$

Table 3 Reported efficiencies $M$ for a conventional washing process [3]

\begin{tabular}{lll}
\hline & $\begin{array}{l}\text { Unfixed, } \\
\text { hydrolysed dyes }\end{array}$ & $\begin{array}{l}\text { Sodium chloride, } \\
\text { urea, caustic soda }\end{array}$ \\
\hline Water seal & 0.2 & 0.5 \\
Unit 1 compartment 1 & 0.2 & 0.4 \\
Unit 1 compartment 2 & 0.1 & 0.2 \\
Rest of unit 1 and unit 2 & 0.05 & 0.2 \\
Units 3 and 4 & 0.05 & 0.25 \\
Units 7 and 8 & 0.05 & 0.2 \\
\hline
\end{tabular}

The values of $M$ can only be used in concentration ranges close to the experimental values in the investigations of Luiken et al. [3].

The concentrations $C_{i}$ and $D_{i}$ in the stationary state can be calculated, as the fabric stream $(V$ in $\mathrm{kg} / \mathrm{h})$ and wash stream $(L$ in $\mathrm{kg} / \mathrm{h})$ are known, using the mass balance (Eqn 4) :

$$
V\left(D_{i-1}-D_{i}\right)+L\left(C_{i+1}-C_{i}\right)=0
$$

The overall washing process is described by wash compartments in series (Figure 3).

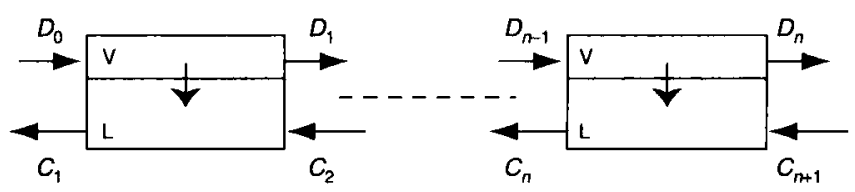

Figure 3 Model of a wash unit consisting of compartments in series

For compartments in series (Figure 3) a relationship for the $D_{n}$ as function of $D_{0}$ and $C_{n+1}$ can be derived out of Eqns 3 and 4 if $M$ is constant (Eqn 5):

$$
D_{n}=\frac{D_{0}[(1 / F)-1]}{(1 / F)-(1 / P)^{n}}+\frac{C_{n+1}\left[1-(1 / P)^{n}\right]}{(1 / F)-(1 / P)^{n}}
$$

where $F$ is the liquor ratio, defined as liquid flow divided by fabric flow, and $P$ is given by (Eqn 6 ):

$$
P=\frac{M}{F}+1-M
$$

The temperature of the fabric and wash water streams are calculated by assuming that the outgoing wash water and the outgoing fabric stream have the same temperature.

\section{Performance of conventional open-width washing range}

The efficiencies for process A1 (Figure 4) are given in Table 3. From this, along with Eqns 3-6, it can be calculated that $15 \mathrm{~m}^{3} / \mathrm{h}$ of water must be used to meet an calculated overall removal efficiency of $87.7 \%$ of unfixed dyes. The fabric stream $V_{\mathrm{w}}$ contains 3.6 and V8 thus $0.443 \mathrm{~g}$ unfixed dyes per $\mathrm{kg}$ dry fabric. The liquor ratio is constant along the washing range, that is, it has a value of 3 .

Even without the use of membranes water can be saved. This has been shown in process A2 (Figure 5). Here unit 1 is connected to the water seal and unit 8 to unit 7 . The connection between units 3 and 2 has not been made because of the difference in the temperatures between these sections; the connection between units 7 and 4 has not been made so that the soap can be retained in the final wash sections. To meet an overall removal efficiency of $87.7 \%$ of unfixed dyes the wash water supply for process A2 is $11.7 \mathrm{~m}^{3} / \mathrm{h}$ with a (constant) liquor ratio of 3.9 .

The concentrations of all components in the incoming fresh water streams are taken to be zero except for sodium chloride which is taken to be $0.25 \mathrm{~g} /$ (according to information kindly provided by Vlisco Helmond).

\section{MODIFICATION OF WASHING PROCESS}

\section{Introduction of membrane separation}

When introducing membranes into the continuous washing process the following points should be considered:

- Which membrane separation step to use

- Where to install the membrane separation in the process

- Where to recycle the wash water after filtration.

To fulfil the aim of recycling the wash water has to be desalinated and decolorised. This can be performed in one step by reverse osmosis (RO). However, should the osmotic pressure become too high to achieve a reasonable transmembrane permeate flux, nanofiltration (NF) has been proposed for concentrating only high molecular weight organic wastes (dyes in this case). The permeate of the nanofiltration is a sodium chloride solution which may not be recycled to the washing process, but may be reused in other contiguous textile finishing processes (e.g. dyeing processes).

The membrane separation processes have been considered by the following two methods: 


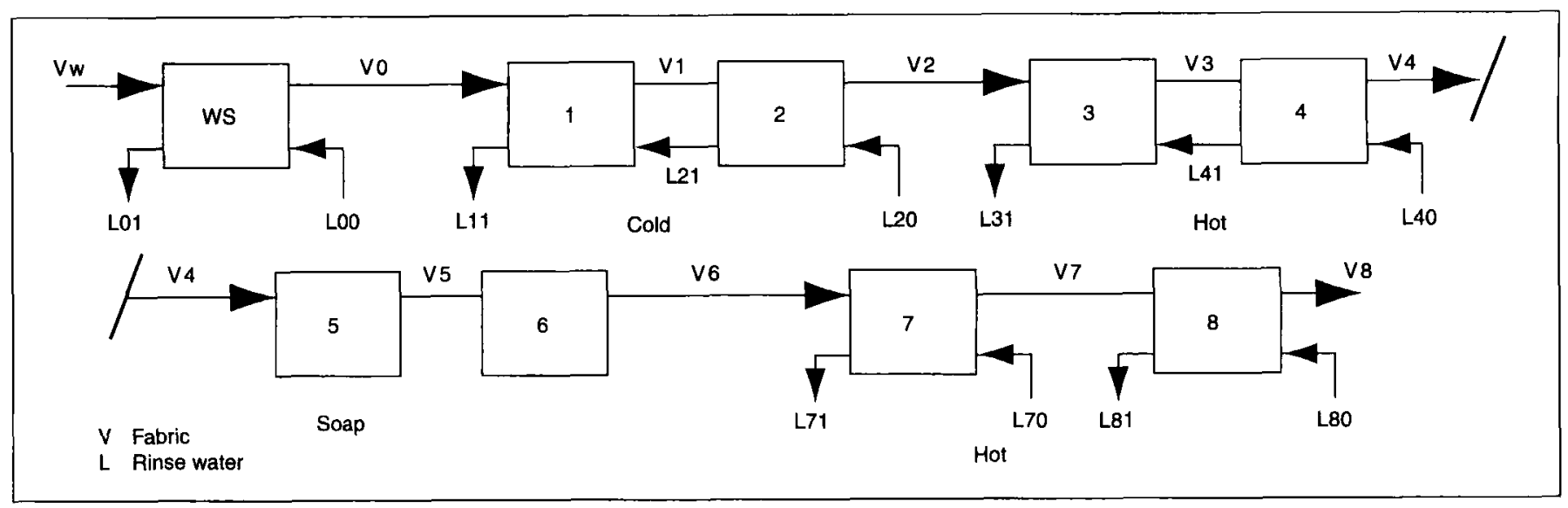

Figure 4 Conventional washing process $\mathrm{A} 1$

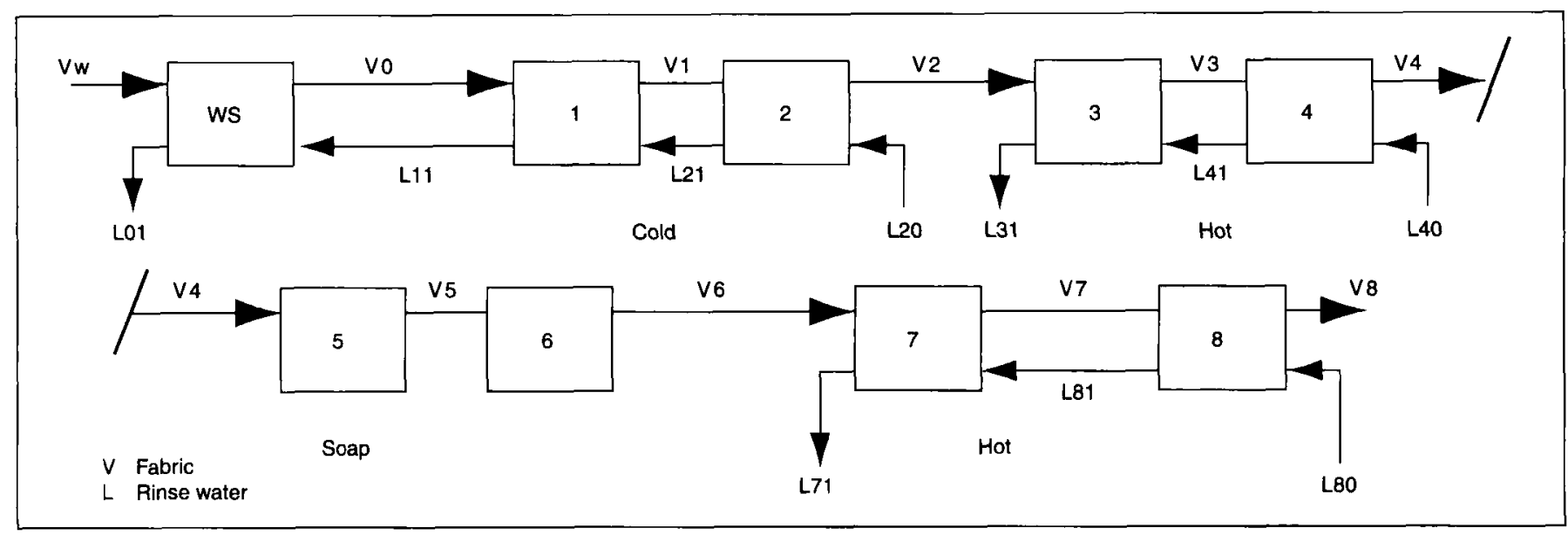

Figure 5 Modified conventional washing process with more countercurrent washing (process A2)

- Process-integrated treatment with recycling of the wash water into the washing process. The aim here is to minimise the use of water and energy. Reverse osmosis is used for this purpose.

- End-of-pipe treatment with no recycling of wash water into the washing process Here the aim is to minimise (or concentrate) the waste streams. Nanofiltration is used for this purpose.

In principle all streams (Figure 1) may be treated by a membrane separation process. However, this is not economically attractive in first instance. The selected approach here is to treat the wash sections separately (cold washing, hot washing before soap addition, hot washing after soap addition). Streams L01, L31 and L71 have been chosen for membrane separation treatment.

A process-integrated method of operation may be carried out in two ways:

(a) Applying complete countercurrent flow in the process by reusing the filtered wash water to a previous wash unit (cf. washing process B, schematically outlined in Figure 6). A heat exchanger is necessary to cool down stream L31 for reuse in the cold section. This heat may be used to partially heat the incoming stream L80. (b) Treating each wash section apart (cf. washing process $\mathrm{C}$, schematically outlined in Figure 7). The wash water from one section (e.g. units 3 and 4) is recycled after filtration to the same wash section. For the cold section this is not recommended as a large temperature rise will occur. Hence, stream L11 instead of stream L01 has been chosen for recycling. The advantages of process $C$ over process $B$ are that no extraneous components (e.g. soap) will enter specific wash sections and that the flexibility of processing is higher as process integration is carried out on a smaller scale. Flexibility of processing may be needed in washing processes which are short in duration and batch-like.

In the calculations the membrane separation steps are characterised by two parameters, namely, the retention and the volume concentration factor. The module configuration and required membrane area are not taken into account. The retention is defined by Eqn 7 :

$$
R=1-\left[\frac{C_{p}}{C_{r}}\right]
$$

where $C_{\mathrm{p}}$ and $C_{\mathrm{r}}$ are the concentrations of the permeate 


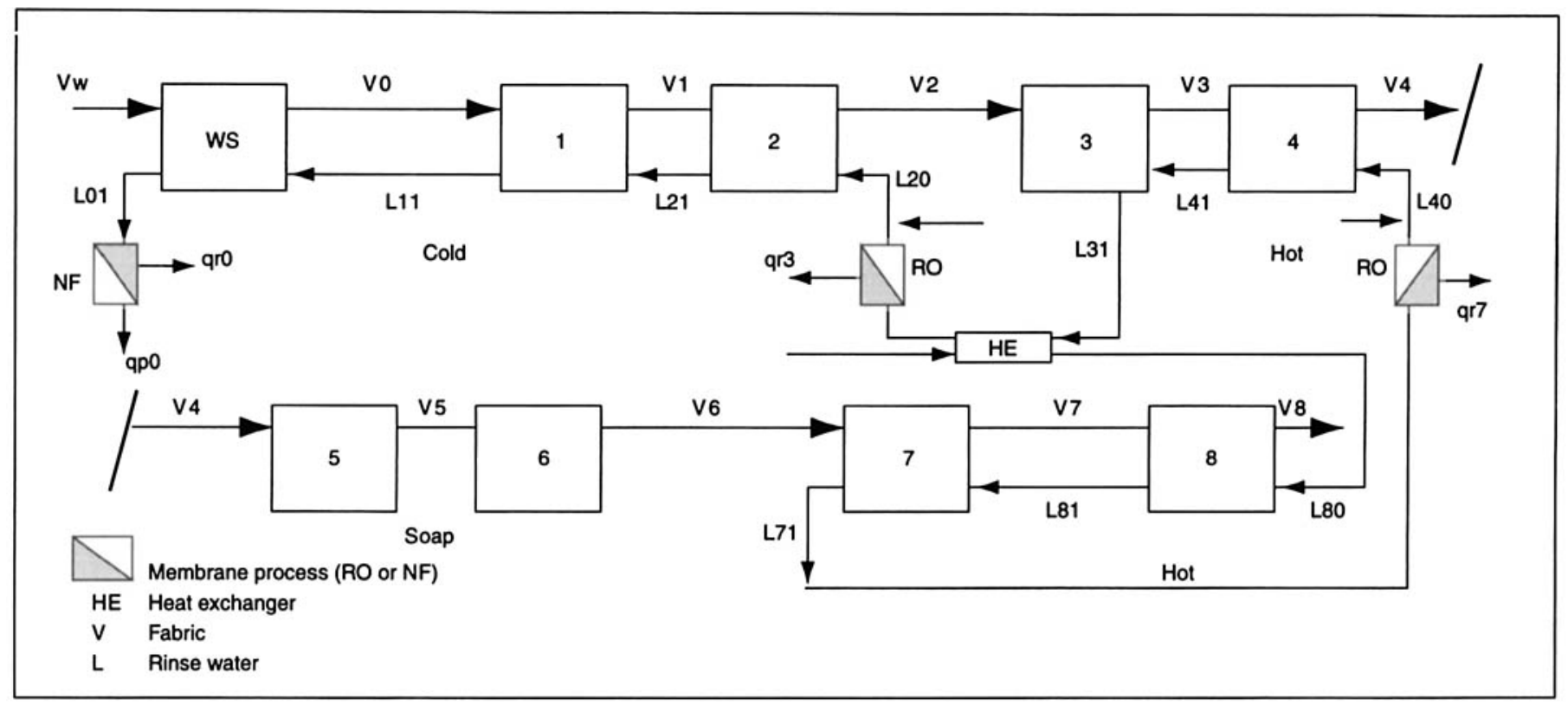

Figure 6 Washing process B

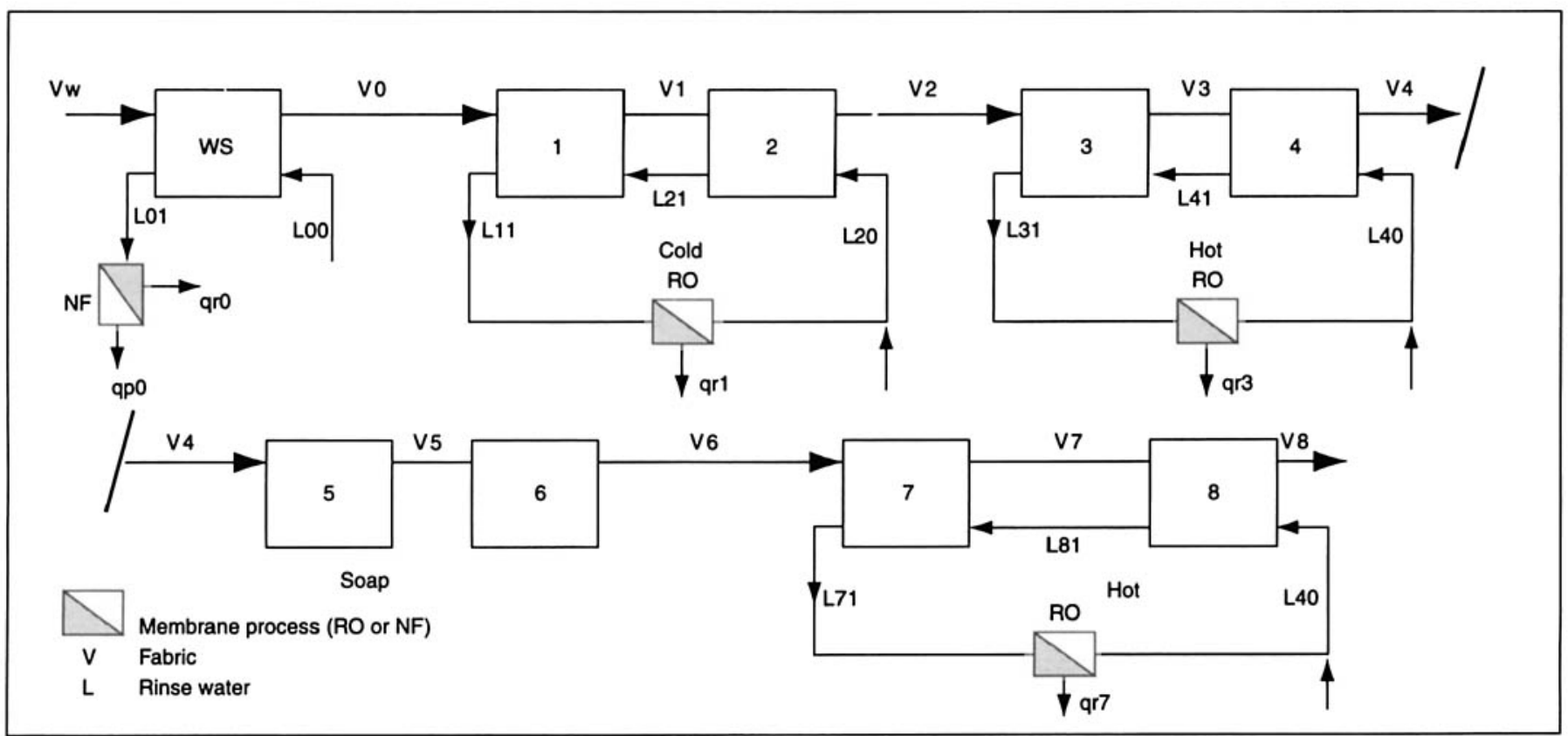

Figure 7 Washing process $\mathrm{C}$

Table 4 Retention of the solutes by different membrane types

\begin{tabular}{lllll}
\hline Membranes & & Dye & $\begin{array}{l}\text { Sodium } \\
\text { chloride }\end{array}$ & $\begin{array}{l}\text { Urea, } \\
\text { caustic soda }\end{array}$ \\
\hline Type 1 & RO & 0.95 & 0.9 & 0.5 \\
Low retention & NF & 0.95 & 0 & 0 \\
Type 2 & RO & 0.99 & 0.99 & 0.5 \\
High retention & NF & 0.99 & 0 & 0 \\
\hline
\end{tabular}

and retentate respectively. The volume concentration factor is defined as the ratio of the flow of the feed entering the separation step to the flow of the retentate leaving the separation step. For both processes $B$ an $C$ the membrane separation steps used are reverse osmosis (streams L11, L31, L71) and nanofiltration (stream L01). For purpose of a sensitivity analysis by alteration of the separation conditions, membranes with different rejection characteristics (Table 4) have been used for both reverse osmosis and nanofiltration. The volume concentration factor is taken to be 10, except for RO of stream qr1 in process $\mathrm{C}$ which is taken to be 2 .

\section{RESULTS AND DISCUSSION}

The main objectives of this case study were to show the benefits and limitations in the use of the membrane separation processes in an open-width textile washing range. The benefits discussed here include: 
- Reduction of water consumption

- Minimisation of waste water volume

- Energy saving.

The limitations considered in this study are:

- Temperature rise in the cold wash sections

- The required transmembrane pressures for membrane processes

- Altered wash water compositions.

\section{Benefits of the modified processes}

\section{Reduction of water consumption}

The aim of the calculations on the modified processes (Figures 6 and 7) was to determine the influence of the characteristics of the applied membrane processes on the water saving by keeping the final quality of the fabric constant (i.e. dye removal $=87.7 \%$ ). Complete water recovery is impossible as water is always discarded by the retentate streams. The reduction of the water consumption in the modified processes is due to the use of membrane separation processes and more countercurrent processing. The latter fact can be shown by comparing process A1 and process A2. Results are summarised in Table 5 .

\section{Waste water volume reduction}

The reduction of waste water volume in processes $B$ and $C$ compared to process A1 are of the same order, $90-93 \%$ (Table 6). This is due to the fact that the volume concentration factor of the NF, where the main part of waste is concentrated, is set at a value of 10 for both processes. The dye concentration in the produced salt water, stream qp0 (Figures 6 and 7), will be increased by a higher volume concentration factor or a lower retention of the dye. The separation between dye and salt thus requires membranes with a high retention of dyes and low retention of the salt under process conditions. More waste reduction can be achieved by combining the stream L01 with the retentate streams from the reverse osmosis processes. The possibilities of this use of nanofiltration
Table 6 Reduction of waste water volume and production of salt water

\begin{tabular}{|c|c|c|c|c|}
\hline \multirow[b]{2}{*}{ Process } & \multicolumn{2}{|c|}{ Waste water } & \multicolumn{2}{|l|}{ Salt water } \\
\hline & Dye (kg/h) & Flow $\left(m^{3} / h\right)$ & Dye $(\mathrm{kg} / \mathrm{h})$ & Flow $\left(m^{3} / h\right)$ \\
\hline $\begin{array}{l}A 1 \\
A 2\end{array}$ & $\begin{array}{l}3.16 \\
3.16\end{array}$ & $\begin{array}{l}15.00 \\
11.70\end{array}$ & & \\
\hline $\begin{array}{l}\text { B1 } \\
\text { B2 }\end{array}$ & $\begin{array}{l}2.41 \\
2.97\end{array}$ & $\begin{array}{l}1.42 \\
1.23\end{array}$ & $\begin{array}{l}0.75 \\
0.19\end{array}$ & $\begin{array}{l}4.26 \\
3.69\end{array}$ \\
\hline $\begin{array}{l}\mathrm{C} 1 \\
\mathrm{C} 2\end{array}$ & $\begin{array}{l}2.94 \\
3.10\end{array}$ & $\begin{array}{l}1.52 \\
1.11\end{array}$ & $\begin{array}{l}0.22 \\
0.06\end{array}$ & $\begin{array}{l}4.56 \\
3.33\end{array}$ \\
\hline
\end{tabular}

technology have not yet been identified and more research is required.

\section{Energy saving}

Reduction of energy consumption in the washing process occurs as a result of a lower hot water intake. However, with decreasing fresh hot water intake, more additional heating in the wash units will be necessary. Corrections for these conditions were necessary in process $C$. The energy saving in the modified processes without extra heat exchange is approximately $30-50 \%$ (Table 5).

The energy saving in the modified processes seems promising but the same saving may be reached by applying heat exchangers only, instead of membranes in combination with heat exchangers. Furthermore, the membrane processes will increase the energy demand as high pressures are needed. The energy demand for such processes, however, is quite low: approximately $3-5 \mathrm{kWh}$ per $\mathrm{m}^{3}$ permeate and thus the increase is approximately $12-25 \mathrm{~kW}$ per membrane system.

\section{Limitations of the modified processes}

Temperature rise in the cold wash section

In process $C$ the temperature of the wash water in the first compartment of the first unit is comparable to the temperature in the conventional process. In process $B$ this

Table 5 Fresh water use and energy use

\begin{tabular}{llllll}
\hline & Rejection by & $\begin{array}{l}\text { Fresh water } \\
\text { use (cold) } \\
\left(\mathrm{m}^{3} / \mathrm{h}\right)\end{array}$ & $\begin{array}{l}\text { Fresh water } \\
\text { use }(\text { warm }) \\
\left(\mathrm{m}^{3} / \mathrm{h}\right)\end{array}$ & $\begin{array}{l}\text { Hourly energy } \\
\text { demand } \\
(\mathrm{kW})\end{array}$ & $\begin{array}{l}\text { Water } \\
\text { saving } \\
(\%)\end{array}$ \\
\hline A1 & & 6 & 9 & 628 & 0 \\
A2 & & 3.9 & 7.8 & 543 & 22 \\
B1 & Low (type 1) & 0.47 & 5.21 & $363^{\mathrm{b}}$ & 62 \\
B2 & High (type 2) & 0.41 & 4.51 & $314^{\mathrm{c}}$ & 67 \\
C1 & Low (type 1) & 7.61 & 1.01 & 415 & 43 \\
C2 & High (type 2) & 5.55 & 0.74 & 338 & 58 \\
\hline
\end{tabular}

a Calculated by the temperature rise needed for the hot section (energy for reverse osmosis process not included)

With heat exchanger $=136 \mathrm{~kW}$

c With heat exchanger $=124 \mathrm{~kW}$ 
temperature is approximately $5-10 \mathrm{deg} C$ higher than the temperature in the conventional process (Table 7). Limitations on this rise in temperature have a negative influence on the water recovery ability of the process (i.e. more water is needed in the water seal for cooling). However, there is no consensus about these limitations among industrialists and researchers in the textile industry. Schulz et al. have claimed that it is not necessary to perform the first washing step at a moderate temperature [2]. They proposed washing with hot water along the washing range in order to diminish the number of wash units. From the process point of view, this method will have improved opportunities for water and energy recycling as complete countercurrent processing in combination with membrane separation can be applied without an additional heat exchanger. Nevertheless, the occurrence of high $\mathrm{pH}(10)$ and high temperatures $\left(80^{\circ} \mathrm{C}\right)$ cannot be tolerated by commercial polymeric membranes.

Table 7 Osmotic pressure differences $(\Delta I)$ between retentate and permeate in membrane systems and temperature rise in first compartment of first unit

\begin{tabular}{lllll}
\hline & $\begin{array}{l}\Delta \Pi \text { qr1 } \\
\text { Process }\end{array}$ & $\begin{array}{l}\Delta \Pi \mathrm{qr} 3 \\
\text { (bar) }\end{array}$ & $\begin{array}{l}\Delta \Pi \mathrm{qr} 7 \\
(\mathrm{bar})\end{array}$ & $\operatorname{Temp}\left({ }^{\circ} \mathrm{C}\right)$ \\
\hline A1 & & & & 25.4 \\
A2 & & & & 24.2 \\
B1 & & 8.0 & 1.4 & 31.5 \\
B2 & & 16.4 & 2.7 & 32.3 \\
C1 & $25.5^{\mathrm{a}}$ & 11.6 & 2.8 & 23.5 \\
C2 & $39.2^{\mathrm{a}}$ & 19.6 & 3.0 & 25.9 \\
\hline
\end{tabular}

a Volume concentration factor is 2 instead of 10

Required transmembrane pressure for membrane processes The transmembrane pressure $\Delta P(\mathrm{bar})$ required to obtain a reasonable permeate flux $J_{\mathrm{v}}\left(\mathrm{V} / \mathrm{m}^{2} \mathrm{~h}\right)$ in reverse osmosis is determined by both membrane and fluid properties. A rough estimate of this flux can be given by Eqn 8 [7]:

$$
J_{\mathrm{v}}=A(\Delta P-\Delta \Pi)
$$

where $A$ is the (clean water) permeability of the membrane. The influence of the fluid properties is described in this study by the osmotic pressure difference $\Delta \Pi$ (bar) (Eqn 9):

$$
\Delta \Pi=R T\left(C_{\mathrm{r}}-C_{\mathrm{p}}\right)
$$

where $R$ is the gas constant and $T$ the temperature. $C_{\mathrm{r}}$ and $C_{p}$ are the sum of the concentrations $(\mathrm{mol} / \mathrm{l})$ of all solutes for retentate and permeate respectively.

Too much flux decline due to elevated osmotic pressure differences may be avoided by:

(a) decreasing the volume concentration factor, in which case the retentate concentration $C_{r}$ will decrease, or (b) decreasing the rejection of the solutes by the membrane, in which case the permeate concentration $C_{\mathrm{p}}$ will increase.

The first measure, a lower volume concentration factor, has already been taken in the RO unit, treating stream L11 of processes $C$ (Figure 7). However, the osmotic pressure of the retentate is still high (over 25 bar). This RO process is therefore not recommended. The effect of the second measure can be shown by comparing the osmotic pressure differences $(\Delta I)$ between retentate and permeate of processes $\mathrm{C} 1$ and $\mathrm{B} 1$ with $\mathrm{C} 2$ and $\mathrm{B} 2$. Treating a stream with high rejection membranes results in higher osmotic pressure differences. The difference in $\Delta \Pi$ between processes $B$ and $C$ is mainly due to the stronger accumulation of urea in processes $C$.

\section{Alteration of the wash conditions}

Recycling of process water leads to (unwanted) accumulation of components which are not rejected by the membranes. These components may have an influence on the washing out efficiency of other components. In this empirical model for the washing process, the influences of sodium chloride, urea and caustic soda concentrations on the washing out efficiency of the dyes are not implemented. However, it is known from practice that sodium chloride does have an influence on the washing performance [3].

The sodium chloride concentrations in the wash units 7 and 8 in process $C 2$ (with high rejection membranes) is lower than those in process $\mathrm{A} 1$ and process $\mathrm{B} 2$. The high rejection membranes produce a permeate stream with a lower salt concentration than in the original fresh water used in the conventional process. Therefore, very high rejection membranes (over $99 \% \mathrm{NaCl}$ rejection) are not necessary here.

Appendix A shows dye concentration, sodium chloride concentration and $\mathrm{pH}$, each as function of the position in the washing range. The differences of the concentrations between the conventional and the modified processes are small, so it can be concluded that the process model may be used here.

The $\mathrm{pH}$ in the hot section of process $\mathrm{C}$ is calculated to be higher than the $\mathrm{pH}$ in the conventional process and process $B$, because of the higher concentration of caustic soda. This may enhance the unwanted hydrolysation reaction of already fixed dyes. Furthermore, the membrane materials can be damaged at the simultaneous occurrence of high $\mathrm{pH}$ and high temperature. Lowering the $\mathrm{pH}$ by adding acid is thus recommended here.

\section{Fouling of membranes and concentration polarisation}

The required membrane area for a given permeate capacity is determined by the permeate flux. This flux depends on the membrane properties, the transmembrane pressure and the osmotic pressure difference. The osmotic pressure difference has been determined under bulk conditions of retentate and permeate. However, phenomena in the 
boundary layer adjacent to a membrane surface will have more influence on the flux than bulk properties. Solutes rejected by the membrane will accumulate in the boundary layer and increase resistance to permeation. This phenomenon, called concentration polarisation, enhances the fouling of the membrane by adsorption of components on the membrane resulting in a decline of the permeate flux in time. For the waste water considered here, little is known about the fouling-flux behaviour in membrane systems. This is complicated by the fact that this waste water contains auxiliary chemicals such as surfactants. More research on flux decline phenomena will be carried out during the present research project.

\section{CONCLUSIONS}

Recycling of water and energy by the use of processintegrated membrane technology in an open-width textile washing range has been analysed. An empirical process model has been used to determine the concentrations in the process streams and to estimate the possibilities for reusing water and energy and decreasing the total waste volume. Two process modifications of the textile washing range have been suggested. The filtered wash water from a wash step can be recycled to a previous wash step (process $B$ ) or to the same wash step (process C). Process B is better in terms of total water and energy savings and continuous processes. Process $\mathrm{C}$ is more suitable in terms of process flexibility and batch processing.

The water saving in process $B$ is in the range $60-70 \%$ and in process $C$ in the range $50-60 \%$. An additional benefit is energy conservation by reduction of hot water intake. Reduction of waste water volume is the most attractive element using membrane separation, as draining this dyecontaining waste water will be restricted in the nearby future. This reduction is about $90 \mathrm{vol} \%$ in both processes.

From a processing point of view, the reuse of process water and minimisation of waste volume in a textile washing range by membrane separation are both promising. Important criteria for the applicability of nanofiltration and reverse osmosis in this textile washing process are retentions (of dyes and salt) and membrane fouling. More research will be carried out within the present research project towards understanding these problems.

The authors wish to thank Senter (Ministry of Economic Affairs) for their financial support and A Luiken (TNO Delft) and C J N Rekers (Stork Friesland) for their contribution.

\section{REFERENCES}

1. H J L J van der Linden, J Groot Wassink and H J Vos, Text. Res. J., 54 (1984) 77 .

2. G Schulz, D Fiebig and H Herlinger, Melliand Textilber., 2 (1993) 137.

3. A H Luiken, G J M Schrijer and D W Ravensberger, Recycling of rinse water in rinsing processes of non-fixed reactive dyes, confidential TNO report (1993).

4. Cibacron product literature, Ciba-Geigy.
5. J Pierce, J.S.D.C., 110 (1994) 000

6. H J L J van der Linden and J Groot Wassink, Proc. IFATCC Congress, Barcelona (1975).

7. R Rautenbach and R Albrecht, Membrane processes (Chichester, UK: J Wiley, 1989) 5.

8. R K Sinnott in Coulson \& Richardson's chemical engineering, 2nd Edn, Vol. 6 (Oxford: Pergamon Press, 1993) 489.

Appendlx A Concentrations of dye and salt, and pH in the different streams of the washing process
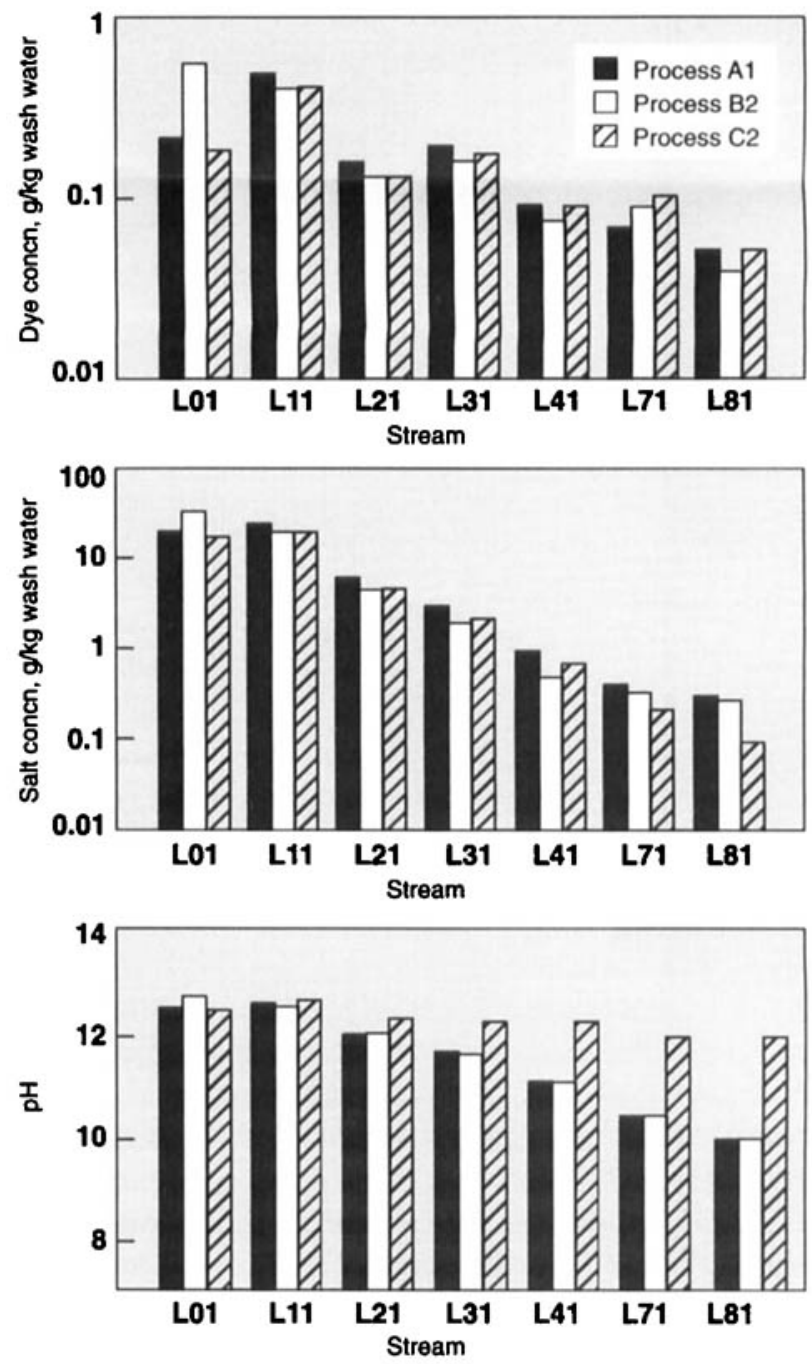

\section{Symbols used}

Symbol Quantity

Unit

$\begin{array}{lll}\Delta \Pi & \text { Osmotic pressure difference } & \text { bar } \\ \Delta P & \text { Trans-membrane pressure } & \text { bar } \\ A & \text { Clean water permeability } & \mathrm{V} /\left(\mathrm{m}^{2} \mathrm{~h} \text { bar }\right) \\ C & \text { Concentration in wash water } & \mathrm{kg} \text { perkg solution } \\ C_{\mathrm{p}} & \text { Permeate concentration } & \mathrm{mol} / \mathrm{m}^{3} \text { solution } \\ C_{r} & \text { Retentate concentration } & \mathrm{mol} / \mathrm{m}^{3} \text { solution } \\ D & \text { Concentration in the fabric } & \mathrm{kg} \mathrm{per} \mathrm{kg} \text { dry fabric } \\ F & \text { Liquor ratio } & \mathrm{kg} \mathrm{water} \mathrm{per} \mathrm{kg} \text { fabric } \\ \mathcal{L} & \text { Transmembrane flux } & \mathrm{V} /\left(\mathrm{m}^{2} \mathrm{~h}\right) \\ L & \text { Wash water flow } & \mathrm{kg} / \mathrm{h} \\ m & \text { Equilibrium constant } & \\ M & \text { Efficiency } & \\ R & \text { Gas constant per mole } & \mathrm{J} / \mathrm{mol} \text {, per degC } \\ T & \text { Temperature } & { }^{\circ} \mathrm{C} \\ V & \text { Fabric flow } & \mathrm{kg} / \mathrm{h}\end{array}$

